\title{
Transit Time of Leukocytes Rolling through Venules Controls Cytokine-induced Inflammatory Cell Recruitment In Vivo
}

\author{
Unsu Jung, ${ }^{\star}$ Keith E. Norman, ${ }^{\star}$ Karin Scharffetter-Kochanek, ${ }^{\ddagger}$ Arthur L. Beaudet, ${ }^{\S}$ and Klaus Ley ${ }^{\star}$ \\ $*$ Department of Biomedical Engineering, University of Virginia School of Medicine, Charlottesville, Virginia 22908; ${ }^{\ddagger}$ Department of \\ Dermatology, University of Cologne, D-50 924 Cologne, Germany; and ${ }^{\S}$ Department of Molecular and Human Genetics, Baylor College \\ of Medicine, Houston, Texas 77030
}

\begin{abstract}
Leukocyte recruitment requires leukocyte rolling, activation, firm adhesion, and transmigration. Injection of the proinflammatory cytokine TNF- $\alpha$ induces expression of E-selectin, interleukin-8, and other adhesion molecules and chemoattractants on the endothelial surface. TNF- $\alpha-$ treated CD18 null mouse cremaster muscle venules show increased leukocyte rolling velocity and reduced leukocyte recruitment efficiency. Leukocyte recruitment in CD18 null but not wild-type mice is significantly blocked by an $\mathrm{mAb}$ to E-selectin. To understand this overlap between adhesion events previously considered separate, we introduce a quantitative analysis of the efficiency of induction of rolling, conversion of rolling to adhesion, and of adhesion to transmigration. We find that $\mathrm{CD} 18$ and E-selectin cooperate to control the time a leukocyte needs to roll through an inflamed area and to convert rolling to firm adhesion. Leukocyte rolling time, defined as the time it takes for a rolling leukocyte to pass through a defined length of a vessel segment, emerges as a unifying parameter determining the efficiency of inducing firm adhesion, which is a rate-limiting step controlling leukocyte recruitment in inflammation. We conclude that leukocytes integrate chemoattractant signals while rolling along the endothelial surface until they reach a critical level of activation and become firmly adherent. $(J$. Clin. Invest. 1998. 102:1526-1533.) Key words: inflammation • rolling • integrin • selectin $\bullet$ CD18 • intravital microscopy
\end{abstract}

\section{Introduction}

Leukocyte adhesion during inflammation is thought to proceed in a cascade-like fashion, in which selectins are responsible for leukocyte capture and rolling, and integrins for mediating firm adhesion and transmigration $(1,2)$. The current paradigm holds that rolling and adhesion are separate, sequential steps in the adhesion cascade, because blocking the selec-

Address correspondence to Klaus Ley, M.D., University of Virginia Medical School, Department of Biomedical Engineering, Health Sciences Center, Box 377, Charlottesville, VA 22908. Phone: 804-9241722; FAX: 804-982-3870; E-mail: kfl3f@virginia.edu Keith E. Norman's present address is Section of Vascular Biology, University of Sheffield, Sheffield S5 7AY, United Kingdom.

Received for publication 16 April 1998 and accepted in revised form 1 September 1998.

J. Clin. Invest.

(C) The American Society for Clinical Investigation, Inc. 0021-9738/98/10/1526/08 \$2.00

Volume 102, Number 8, October 1998, 1526-1533

http://www.jci.org tin class of adhesion molecules (3-5) or interfering with $\beta_{2}$ integrin (CD18) function $(6,7)$ can each reduce leukocyte accumulation at sites of inflammation.

In a model of inflammation induced by intrascrotal injection of TNF- $\alpha$ in mice, E- and P-selectin expression are induced on the surface of the venular endothelium in the cremaster muscle (8). This expression coincides with the induction of leukocyte rolling in these microvessels (3, 9-11). Although mice deficient in P-selectin demonstrate a deficit in trauma-induced leukocyte rolling primarily during the first hour after exteriorization $(9,12)$, the number of rolling leukocytes after treatment with TNF- $\alpha$ is close to normal in P-selectin-deficient mice (9) and elevated in E-selectin-deficient mice (10). E-selectin preferentially mediates slow leukocyte rolling $(<5 \mu \mathrm{m} / \mathrm{s})$, while P-selectin mediates more rapid leukocyte rolling $(20-50 \mu \mathrm{m} / \mathrm{s})(10,11)$. Based on the absence of rolling and the severe inflammatory defect seen in E- and P-selectin double-deficient mice $(4,5)$, rolling is thought to be required for firm adhesion. However, it is not known why rolling is required for firm adhesion to occur. Current hypotheses include that rolling may be necessary to physically slow down leukocytes because the integrins may have forward reaction rates (on-rates) insufficient to promote leukocyte binding from flow (13). Second, a close geometric proximity may be necessary between the rolling leukocyte and the endothelial surface to allow leukocyte activation by inflammatory chemoattractants such as platelet-activating factor (PAF) ${ }^{1}$ and IL-8 presented on the endothelium to promote subsequent arrest (14). Third, leukocyte rolling may be required to allow a sufficiently long presence of the leukocytes in the area of inflammation so that they can be activated by chemokines during their transit.

Here, we test the hypothesis that the rolling time of leukocytes through inflamed microvessels and hence their exposure time to chemoattractants may determine the efficiency of leukocyte arrest. To investigate this hypothesis, we use mice with a null mutation in the CD18 gene (7). To examine possible cooperative functions of CD18 and E-selectin in leukocyte rolling and firm adhesion, we use function-blocking mAbs to E-selectin in wild-type or CD18 null mice and study the rolling velocities as well as the accumulation of adherent leukocytes in venules and transmigrated leukocytes in the interstitial tissue. Earlier studies have not focused on CD18 and E-selectin and have not defined the efficiency of various steps in the adhesion cascade. Here, we introduce parameters suitable to identify the cause of the inflammatory defects resulting from blockade of CD18 and/or E-selectin. These parameters reflect the net efficiency of conversion from free flowing to rolling, rolling to firm adhesion, and firm adhesion to transmigration (Fig. 1).

1. Abbreviations used in this paper: i.p., intraperitoneal; PAF, plateletactivating factor. 


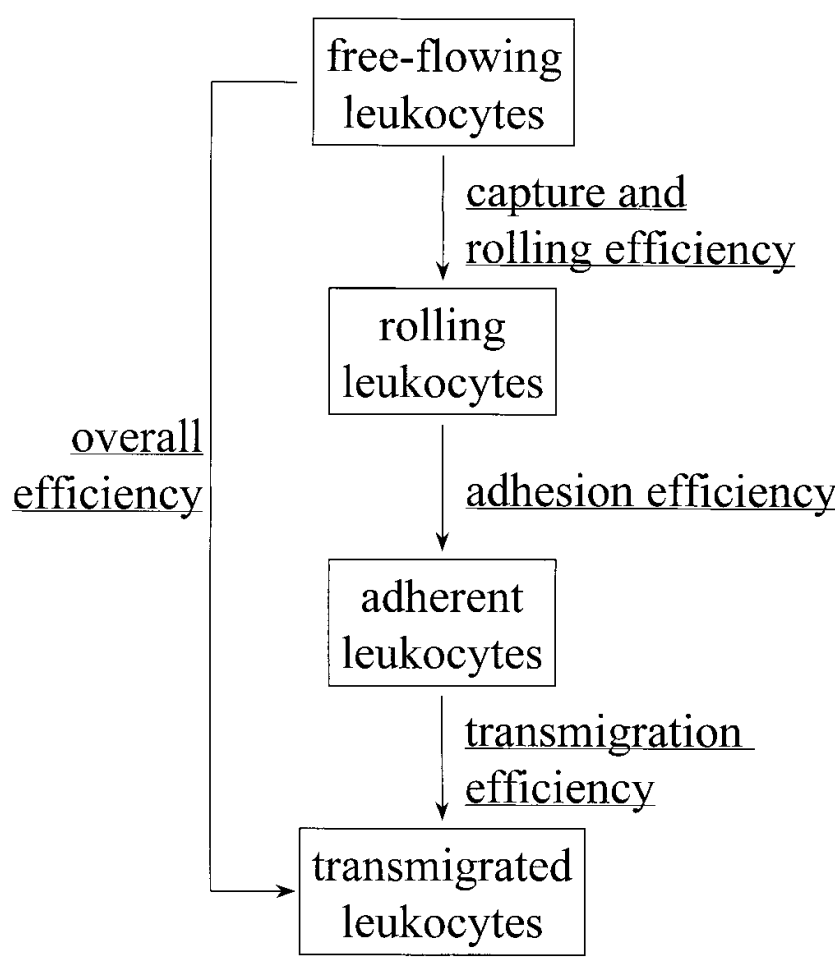

Figure 1. Normalized parameters measuring efficiencies of leukocyte rolling, adhesion, and transmigration. Rolling and capture efficiency were measured as rolling flux fraction. Adherent cells were defined as leukocytes that were not moving for at least $30 \mathrm{~s}$, and their number was expressed per unit inner vessel surface area $\left(\right.$ cells $\left./ \mathrm{mm}^{2}\right)$. Adhesion efficiency was measured as adherent leukocytes $/ \mathrm{mm}^{2}$ per 100 rolling leukocytes/min. Giemsa-stained cremaster muscle whole mounts were used to quantitate transmigrated leukocytes, which were counted in a semicircular area (with a diameter of $141 \mu \mathrm{m}$ ) surrounding each side of a venule and expressed as cells $/ \mathrm{mm}^{2}$. Transmigration efficiency is the ratio of the number of transmigrated divided by adherent intravascular leukocytes. Overall leukocyte recruitment efficiency was defined as the total number of transmigrated leukocytes $/ \mathrm{mm}^{2}$ per 1,000 circulating leukocytes/ $\mu \mathrm{L}$.

An overall inflammation efficiency parameter is defined as the ratio between the concentration of leukocytes in the interstitial tissue surrounding each venule and the concentration of circulating leukocytes.

\section{Methods}

Animals. Male CD18 null mice (mixed 129/Sv $\times$ C57BL/6 background) were obtained from established colonies derived from a gene-targeted founder (7). All mutant mice used in this study were offspring from homozygous F2 intercrosses. Control mice were of matching age and strain.

Antibodies and cytokines. The rat anti-mouse monoclonal antibody to E-selectin, 9A9 ( $\operatorname{IgG} 1$ ), has previously been shown to specifically block E-selectin function in vitro (15) and E-selectin-dependent rolling in vivo (10). mAb 9A9 was a generous gift of Dr. B. Wolitzky (Hoffman-La Roche, Inc., Nutley, NJ). Recombinant murine TNF- $\alpha$ (Genzyme, Cambridge, MA) was injected intrascrotally at a dose of $500 \mathrm{ng}$ per mouse in a volume of $0.3 \mathrm{ml}$ of sterile saline $2 \mathrm{~h}$ before the beginning of the intravital microscopic experiments. In some animals, mAb 9A9 (100 $\mu \mathrm{g}$ per mouse) was administered as an intraperitoneal (i.p.) injection at the time of TNF- $\alpha$ injection.
Intravital microscopy. Mice were anesthetized with an i.p. injection of ketamine hydrochloride $(100 \mathrm{mg} / \mathrm{kg}$, Ketalar; Parke-Davis, Morris Plains, NJ) after pretreatment with sodium pentobarbital (30 $\mathrm{mg} / \mathrm{kg}$ i.p., Nembutal; Abbott Laboratories, North Chicago, IL) and atropine $(0.1 \mathrm{mg} / \mathrm{kg}$ i.p.; Elkins-Sinn, Inc., Cherry Hill, NJ). The trachea was intubated, and one jugular vein was cannulated for administration of anesthetic throughout the intravital microscopic experiment. One carotid artery was cannulated for blood pressure monitoring, blood samples, and systemic mAb injections. Mice were kept at a constant temperature of $37^{\circ} \mathrm{C}$ with a thermo-controlled heating lamp (Physitemp Instruments, Clifton, $\mathrm{NJ}$ ) and received $\sim 0.2$ $\mathrm{mL} / \mathrm{h}$ diluted pentobarbital in saline i.v. to maintain anesthesia and a neutral fluid balance. The cremaster muscle was prepared for intravital microscopy as described (10). The epididymis and testis were gently pinned to the side, exposing the well-perfused cremaster microcirculation. The cremaster muscle was superfused with thermocontrolled $\left(35^{\circ} \mathrm{C}\right)$ bicarbonate-buffered saline. Blood samples $(10 \mu \mathrm{L}$ each) were taken throughout the experiment from the carotid catheter at $\sim 45$-min intervals to analyze systemic leukocyte concentrations. Differential leukocyte counts were obtained by evaluating Kimura-stained blood samples in a hemocytometer.

Microscopic observations were made on an intravital microscope (Axioskop; Zeiss, Thornwood, NY) with a saline immersion objective (SW 40/0.75 numerical aperture). Each venule was observed for $\sim 60 \mathrm{~s}$. Venules with diameters between 20 and $80 \mu \mathrm{m}$ were observed and recorded via a CCD camera system (model VE-1000CD; Dage-MTI, Inc., Michigan City, IN) on a Panasonic S-VHS recorder. Centerline red blood cell velocity was measured using a dual photodiode and a digital on-line cross-correlation program (16). Centerline velocities were converted to mean blood flow velocities by multiplying with an empirical factor of $0.625(17)$. Wall shear rates $\left(\gamma_{\mathrm{w}}\right)$ were estimated as $2.12\left(8 \mathrm{~V}_{\mathrm{b}} / \mathrm{d}\right)$, where $\mathrm{V}_{\mathrm{b}}$ is the mean blood flow velocity, $\mathrm{d}$ is the diameter of the vessel, and 2.12 is a median empirical correction factor obtained from actual velocity profiles measured in microvessels in vivo (18). Microvessel diameters, lengths, and rolling leukocyte velocities were measured using a digital image processing system (16). Each rolling leukocyte passing a line perpendicular to the vessel axis was counted, and leukocyte rolling flux was expressed as leukocytes per minute. Leukocyte rolling velocities were measured over a constant 2-s time window (19). Rolling velocities of 10 leukocytes were measured in each venule. Rolling times for leukocytes rolling through a $100-\mu \mathrm{m}$ venular segment were calculated by dividing $100 \mu \mathrm{m}$ by the leukocyte rolling velocities. Adherent cells were defined to be the leukocytes that were not moving for at least $30 \mathrm{~s}$. The total number of adherent cells were measured for each venule and expressed per unit area of inside surface area of the venule. The surface area was calculated from diameter and length assuming cylindrical geometry of the venule.

Normalized parameters. Since leukocyte recruitment is understood to be a multistep process requiring margination, rolling, firm adhesion, and transendothelial migration, we defined a series of normalized parameters aimed at quantitatively describing the efficacy of each of these steps. As in previous publications from our laboratory $(10,20)$, rolling leukocyte flux fraction was obtained by dividing leukocyte rolling flux by total leukocyte flux through the same microvessel. Leukocyte rolling flux fraction relates the number of rolling leukocytes to the number available in the systemic circulation and therefore reflects rolling efficiency. Similarly, we normalized the number of adherent leukocytes with the rolling leukocyte flux (adherent cells $/ \mathrm{mm}^{2}$ per 100 rolling cells $/ \mathrm{min}$ ). This parameter relates the number of adherent cells to the rolling leukocyte pool available in the same vessel. To obtain a parameter for transmigration efficiency, we divided the number of extravasated leukocytes by the number of intravascular leukocytes (transmigrated/intravascular cells). Finally, we calculated the overall efficiency of the inflammatory process by expressing the number of transmigrated leukocytes per $\mathrm{mm}^{2}$ per 1,000 circulating leukocytes. This parameter reflects the net recruitment efficiency including all steps of the leukocyte recruitment process. 
Histology. To differentiate intravascular and interstitial leukocytes, whole mounts of cremaster muscle were prepared by dropping $4 \%$ paraformaldehyde in $0.1 \mathrm{M}$ phosphate buffer ( $\mathrm{pH} 7.4$ ) onto the tissue while still mounted on the cremaster stage for intravital microscopy. The cremaster muscle was removed, mounted flat on a polyL-lysine treated glass slide and air dried for 5-10 min, followed by fixation in $4 \%$ paraformaldehyde in $0.1 \mathrm{M}$ phosphate buffer $(\mathrm{pH} 7.4)$ for $24 \mathrm{~h}$ at $4^{\circ} \mathrm{C}$. After fixation, the tissue was washed three times in $0.1 \mathrm{M}$ phosphate buffer with 5\% ethanol, stained with Giemsa stain (Sigma Chemical Co., St. Louis, MO) at room temperature for 5-10 min, and differentiated in $0.01 \%$ acetic acid for contrast. The differentiated slides were sequentially washed in water, $75 \%, 95 \%$, and $100 \%$ ethanol, and fresh xylene, followed by mounting in Permount. The Giemsa-stained cremaster muscles were observed using a Zeiss microscope with a $100 \times, 1.4$ numerical aperture oil immersion objective. Intravascular and interstitial leukocytes were counted and differentiated into neutrophils, eosinophils, and mononuclear cells. The interstitial tissue observed was the semicircular area (with a diameter of $141 \mu \mathrm{m}$ ) surrounding each side of a venule.

Statistics. Average leukocyte rolling flux fractions, leukocyte adhesion, leukocyte rolling velocities, systemic leukocyte counts, and differentials between groups were compared using one-wayANOVA Kruskal-Wallis multiple comparison test. Statistical significance was set at either $P<0.05$ or $P<0.01$.

\section{Results}

Hemodynamics and systemic leukocyte counts. Leukocyte rolling, adhesion, and transmigration in response to $\mathrm{TNF}_{-} \alpha$ injected $2 \mathrm{~h}$ before intravital microscopy were investigated in 93 venules of 13 wild-type and 137 venules of 10 CD18 null mice (diameter, $40 \pm 1 \mu \mathrm{m}$, mean \pm SEM, centerline blood flow velocity, $1.2 \pm 0.03 \mathrm{~mm} / \mathrm{s}$, calculated wall shear rate, $533 \pm 12 \mathrm{~s}^{-1}$ ), these values were not significantly different among the experimental groups (Table I). The systemic leukocyte concentration in CD18 null mice $\left(32,500 \pm 5,500 \mu \mathrm{L}^{-1}\right)$ was approximately 12 fold higher than in wild-type mice $\left(2,700 \pm 400 \mu \mathrm{L}^{-1}\right)$. Pretreatment with a saturating dose of the E-selectin mAb, 9A9, did not significantly change the systemic leukocyte counts in either wild-type or CD18 null mice.

Leukocyte rolling, adhesion and transmigration and their efficiencies. Consistent with the highly elevated circulating leukocyte counts, rolling flux in cremaster muscle venules after stimulation with $\mathrm{TNF}-\alpha$ was greatly increased in CD18 null mice $(290 \pm 25$ cells $/ \mathrm{min})$ compared with the wild-type mice $(53 \pm 29$ cells $/ \mathrm{min})$ (Fig. 2 A). Although CD18 null mice had a higher leukocyte rolling flux than wild-type mice, the rolling flux fraction was not significantly different (Fig. $2 B$ ). Thus, the efficiency of leukocyte capture and rolling in venules of CD18 null mice after $\mathrm{TNF}-\alpha$ treatment did not change from wildtype mice. Pretreatment with mAb 9A9 at the time of TNF- $\alpha$ injection increased leukocyte rolling flux and flux fraction in both wild-type ( $\sim 1.8$-fold increase to $99 \pm 23$ cells $/ \mathrm{min}, P<$ $0.05)$ and CD18 null ( $\sim 1$.4-fold increase to $406 \pm 18$ cells $/ \mathrm{min}$, $P<0.05)$ mice (Fig. 2, $A$ and $B$ ). This is consistent with previous observations (10). In both wild-type and CD18 null mice pretreated with mAb 9A9, leukocyte rolling was almost completely blocked by injection of the P-selectin mAb, RB40.34 (data not shown), confirming that leukocyte rolling in this model depends on E- and P-selectins.

The number of firmly adherent leukocytes per unit surface area $3 \mathrm{~h}$ after TNF- $\alpha$ was not significantly different between nontreated or mAb 9A9 pretreated wild-type mice (Fig. $2 C$ ). This indicates that in the presence of all other adhesion molecules, E-selectin is not necessary for a normal level of leukocyte adhesion in response to TNF- $\alpha$. Surprisingly, more leukocytes become adherent in TNF- $\alpha$-treated CD18 null mice $(P<$ 0.05 , Fig. $2 C$ ) compared with wild-type mice with or without mAb 9A9 pretreatment. Pretreatment of CD18 null mice with mAb 9A9 significantly reduced firm adhesion (by $47 \%, P<$ 0.05, Fig. $2 C$ ), indicating that in the absence of CD18 leukocyte adhesion requires E-selectin.

Investigation of leukocyte adhesion efficiency as reflected by the normalized parameters shows that $3,381 \pm 523 \mathrm{cells} / \mathrm{mm}^{2}$ were adherent in TNF- $\alpha$-treated wild-type mice for every 100 rolling leukocytes passing the same vessel segment per minute. When E-selectin was blocked, this number was reduced by $38 \%(P<0.05$, Fig. $2 D)$. We observed a similar reduction (by $33 \%$ compared with wild-type mice) in adhesion efficiency in CD18 null mice (Fig. 2 D). Leukocyte adhesion was least efficient when CD18 null mice were pretreated with mAb 9A9 $\left(379 \pm 31\right.$ cells $/ \mathrm{mm}^{2}$ adherent for every 100 rolling cells per minute), a reduction by $92 \%$ compared with nontreated wildtype mice $(P<0.05$, Fig. $2 D)$. In wild-type mice with and without $\mathrm{mAb} 9 \mathrm{~A} 9$ pretreatment, as well as nontreated CD18 null mice, $>90 \%$ of leukocytes within the venules were neutrophils (Table II). However, when CD18 null mice were pretreated with mAb 9A9, there was a significant decrease in the fraction of neutrophils to $74 \pm 3 \%$ (Table II). This suggests that granulocyte recruitment is impaired more severely than mononuclear cell recruitment in the absence of both CD18 and E-selectin function.

CD18 integrins have previously been implicated in leukocyte transmigration through endothelium in vitro $(21,22)$ and in vivo (23). A defect in leukocyte transmigration could cause an increased level of intravascular, adherent cells in CD18 null mice if these leukocytes cannot leave the venule. Therefore, we determined the number of leukocytes that had extravasated into the cremaster muscle tissue surrounding the venules. Surprisingly, CD18 null mice showed an increased

Table I. Systemic Leukocyte Counts and Hemodynamic Data

\begin{tabular}{|c|c|c|c|c|}
\hline & \multicolumn{2}{|c|}{ Wild-type } & \multicolumn{2}{|c|}{ CD18 null } \\
\hline & No mAb & E-sel. mAb & No mAb & E-sel. mAb \\
\hline Systemic leukocyte counts $\left(\mu \mathrm{L}^{-1}\right)$ & $2715 \pm 388$ & $2963 \pm 571$ & $32530 \pm 5489$ & $25658 \pm 4025$ \\
\hline Number of mice $(\mathrm{N})$ & 5 & 8 & 5 & 5 \\
\hline Number of venules (n) & 30 & 63 & 46 & 91 \\
\hline Average diameter $(\mu \mathrm{m})$ & $37.0 \pm 1.9$ & $42.1 \pm 1.4$ & $42.2 \pm 2.2$ & $37.7 \pm 1.3$ \\
\hline Average shear rates $\left(\mathrm{s}^{-1}\right)$ & $614 \pm 35$ & $461 \pm 22$ & $467 \pm 26$ & $597 \pm 19$ \\
\hline
\end{tabular}



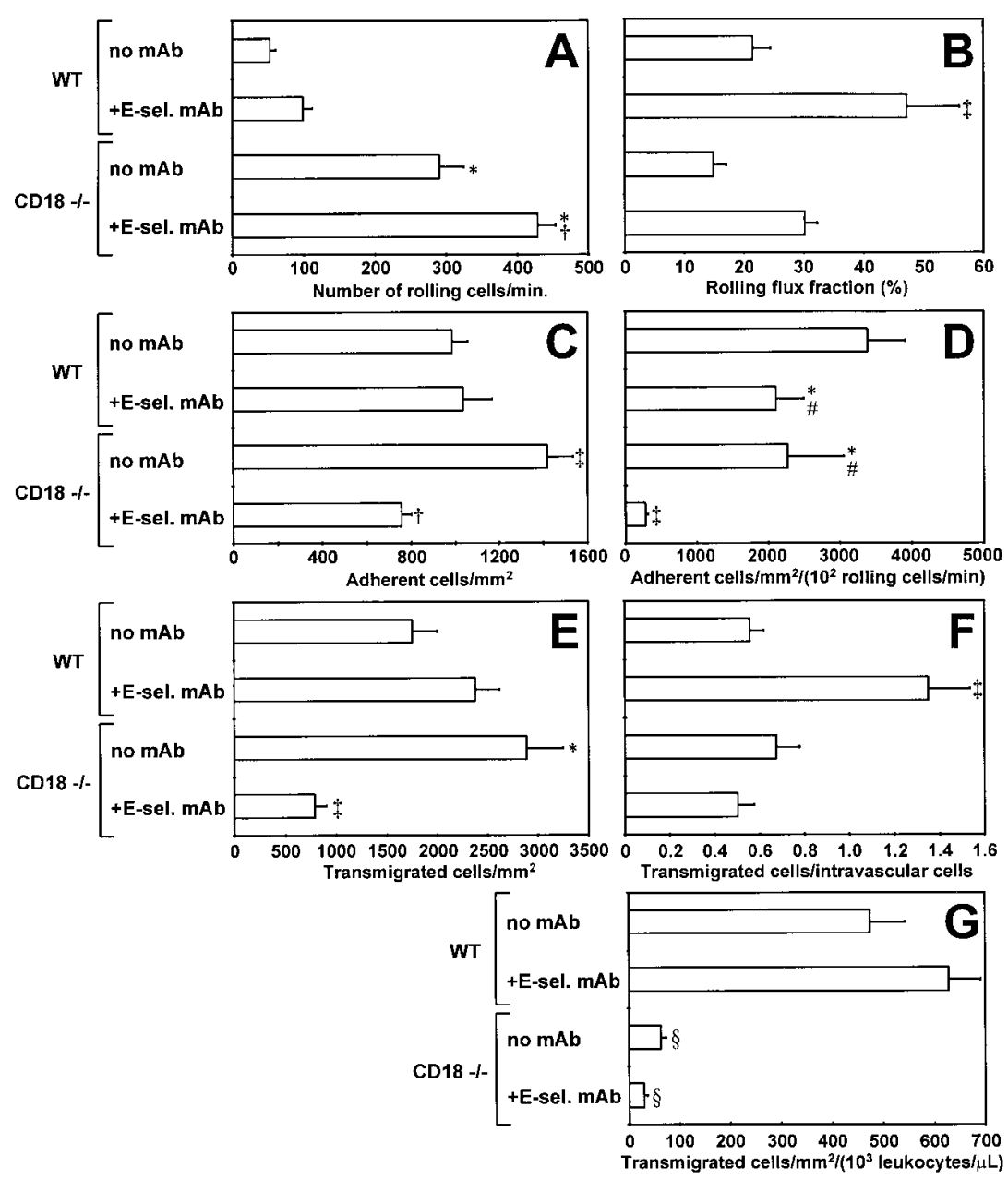

Figure 2. Leukocyte rolling, adhesion, and transmigration in TNF- $\alpha$-treated cremaster muscle venules of wild-type $(W T)$ and CD18 null mice $(C D 18-/-)$. (A) Leukocyte rolling flux (number of rolling cells/min), $(B)$ rolling flux fraction, $(C)$ leukocyte adhesion per unit surface area (adherent cells $\left./ \mathrm{mm}^{2}\right),(D)$ adhesion efficiency (adherent cells $/ \mathrm{mm}^{2}$ per 100 rolling cells/min), (E) leukocyte accumulation per unit area (transmigrated cells/ $\left.\mathrm{mm}^{2}\right),(F)$ transmigration efficiency (transmigrated cells/intravascular cells), and $(G)$ overall leukocyte recruitment efficiency (transmigrated cells $/ \mathrm{mm}^{2}$ per 1,000 leukocytes $/ \mu \mathrm{L}$ ) in wild-type $(W T)$ and CD18 null (CD18-/-) mice with and without E-selectin mAb 9A9. Data represented as mean \pm SEM derived from 17 to 94 venules. *, Significantly different from $\mathrm{WT} ;{ }^{\dagger}$, significantly different from CD18 -/-; ${ }^{\ddagger}$, significantly different from all other groups; , significantly different from CD18 pretreated with E-selectin mAb; ${ }^{\S}$, significantly different from WT and WT pretreated with E-selectin $\mathrm{mAb}(P<0.05)$ by using a StudentNewman-Keuls multiple comparison test (oneway-ANOVA). level of leukocyte accumulation in interstitial tissues compared with wild-type mice $(P<0.05$, Fig. $2 E)$. When E-selectin function was blocked by mAb 9A9 in CD18 null mice, the leukocyte accumulation in interstitial tissues was reduced by $73 \%(P<$ 0.05 , Fig. $2 E$ ). This can be attributed to the lower level of leukocyte adhesion observed in CD18 null mice pretreated with $\mathrm{mAb} 9 \mathrm{~A} 9$, because the number of transmigrated cells expressed as a fraction of the number of intravascular leukocytes (transmigration efficiency) was not reduced by absence of CD18 and/or E-selectin function (Fig. 2 F). Our data suggest that some of the earlier studies did not account for reduced adhesion as an indirect cause for reduced transmigration. The composition of transmigrated leukocytes was similar to the distribution seen inside microvessels (Table II).

Although leukocytes in CD18 null mice were being recruited at a level comparable with that observed in wild-type mice, the overall efficiency of leukocyte recruitment was markedly reduced in CD18 null mice (Fig. $2 \mathrm{G}$ ). Blocking E-selectin function with mAb 9A9 significantly decreased the recruitment efficiency in CD18 null mice $(P<0.05$, Fig. $2 G)$

Table II. Summary of Intravascular and Transmigrated Leukocyte Differentials after TNF- $\alpha$ Treatment in Wild-type and CD18 Null Mice with or without E-Selectin mAb $9 A 9$ Pretreatment

\begin{tabular}{|c|c|c|c|c|}
\hline & \multicolumn{2}{|c|}{ Wild-type } & \multicolumn{2}{|c|}{ CD18 null } \\
\hline & No mAb & E-sel. mAb & No mAb & E-sel. mAb \\
\hline \multicolumn{5}{|c|}{ Intravascular leukocytes (rolling and adherent) } \\
\hline \% Neutrophils & $90 \pm 1$ & $91 \pm 2$ & $92 \pm 1$ & $74 \pm 3 *$ \\
\hline$\%$ Mononuclear cells & $8 \pm 1$ & $6 \pm 1$ & $7 \pm 1$ & $26 \pm 2 *$ \\
\hline \multicolumn{5}{|l|}{ Transmigrated leukocytes } \\
\hline$\%$ Neutrophils & $89 \pm 3$ & $81 \pm 3$ & $92 \pm 1$ & $65 \pm 5^{*}$ \\
\hline$\%$ Mononuclear cells & $10 \pm 3$ & $9 \pm 1$ & $7 \pm 1$ & $30 \pm 5^{*}$ \\
\hline
\end{tabular}

All values expressed as mean \pm SEM. * Significantly different from all other groups $(P<0.05)$. 
but not in wild-type mice. These results show that CD18 and E-selectin cooperate to promote efficient leukocyte recruitment in response to cytokine treatment.

Leukocyte rolling velocity and rolling time. To understand the causes underlying this previously unappreciated cooperation between E-selectin and CD18 in converting rolling to firm adhesion, we investigated leukocyte rolling velocities. Leukocyte rolling velocities in vivo vary widely, depending on the tissue, the inflammatory stimulus, and the selectins expressed $(10,11,24)$. In wild-type mice after $2-3-\mathrm{h} \mathrm{TNF}-\alpha$ treatment, leukocytes rolled at a mean velocity of $6.8 \pm 0.4 \mu \mathrm{m} / \mathrm{s}$, which was increased to $16.1 \pm 0.5 \mu \mathrm{m} / \mathrm{s}$ by E-selectin $\mathrm{mAb}$, consistent with previous data (10). The rolling velocity distribution in wild-type mice showed a peak between 0 to $5 \mu \mathrm{m} / \mathrm{s}$, which was shifted to $5-15 \mu \mathrm{m} / \mathrm{s}$ in the mAb 9A9-pretreated group (Fig. 3 $A)$. In spite of the shift of the mean, the variation in the rolling velocity distribution remained almost constant as indicated by the coefficients of variation (SD/mean, 8.9 for nontreated and 8.4 for pretreated with mAb $9 A 9$ in wild-type mice, respectively). CD18 null mice showed an even higher mean leukocyte rolling velocity $(22.7 \pm 0.8 \mu \mathrm{m} / \mathrm{s})$ than wild-type mice pretreated with mAb 9A9 $(P<0.01)$. The peak of the rolling velocity distribution in CD18 null mice was not different from that found in nontreated wild-type mice (Fig. $3 A$ ). However, the frequency of slow-rolling leukocytes $(0-5 \mu \mathrm{m} / \mathrm{s})$ was reduced in CD18 null mice (17\% of rolling leukocytes) compared with nontreated wild-type mice $(61 \%$ of rolling leuko- cytes). There was a larger fraction of leukocytes rolling at $>30$ $\mu \mathrm{m} / \mathrm{s}$ in CD18 null mice (30\% of rolling leukocytes) than either nontreated ( $2 \%$ of rolling leukocytes) or mAb 9A9 pretreated wild-type mice ( $10 \%$ of rolling leukocytes). Therefore, the increase in mean rolling velocity observed in CD18 null mice was primarily due to a higher variance in the rolling velocity distribution (coefficient of variation 15.7 compared with 8.9 in wild-type mice).

Pretreatment of CD18 null mice with mAb 9A9 resulted in a further dramatic increase in rolling velocity to $39.2 \pm 0.8 \mu \mathrm{m} / \mathrm{s}$. Mean rolling velocity in CD18 null mice pretreated with $\mathrm{mAb}$ 9A9 was almost six times higher than in nontreated wild-type mice. In addition, the rolling velocity distribution peak was shifted from $0-5 \mu \mathrm{m} / \mathrm{s}$ to $10-15 \mu \mathrm{m} / \mathrm{s}$ (Fig. $3 A$ ). CD18 null mice pretreated with $\mathrm{mAb} 9 \mathrm{~A} 9$ showed the largest population of leukocytes rolling at velocities $>30 \mu \mathrm{m} / \mathrm{s}(55 \%$ of rolling leukocytes). Thus, the combined absence of CD18 and blockade of E-selectin function resulted in a greater shift to the right combined with an increase in variation in the leukocyte rolling velocity distribution. This shows that both CD18 and E-selectin mediate slow leukocyte rolling in $\mathrm{TNF}-\alpha$-treated venules. Since leukocyte adhesion $(24,25)$ and rolling velocity $(26,27)$ are known to be influenced by the wall shear rate, we investigated whether the prevailing shear rate may have influenced the observed adhesion efficiencies. No systematic correlation was found between shear rate and level of adhesion (data not shown), indicating that the shear rate did not significantly af-
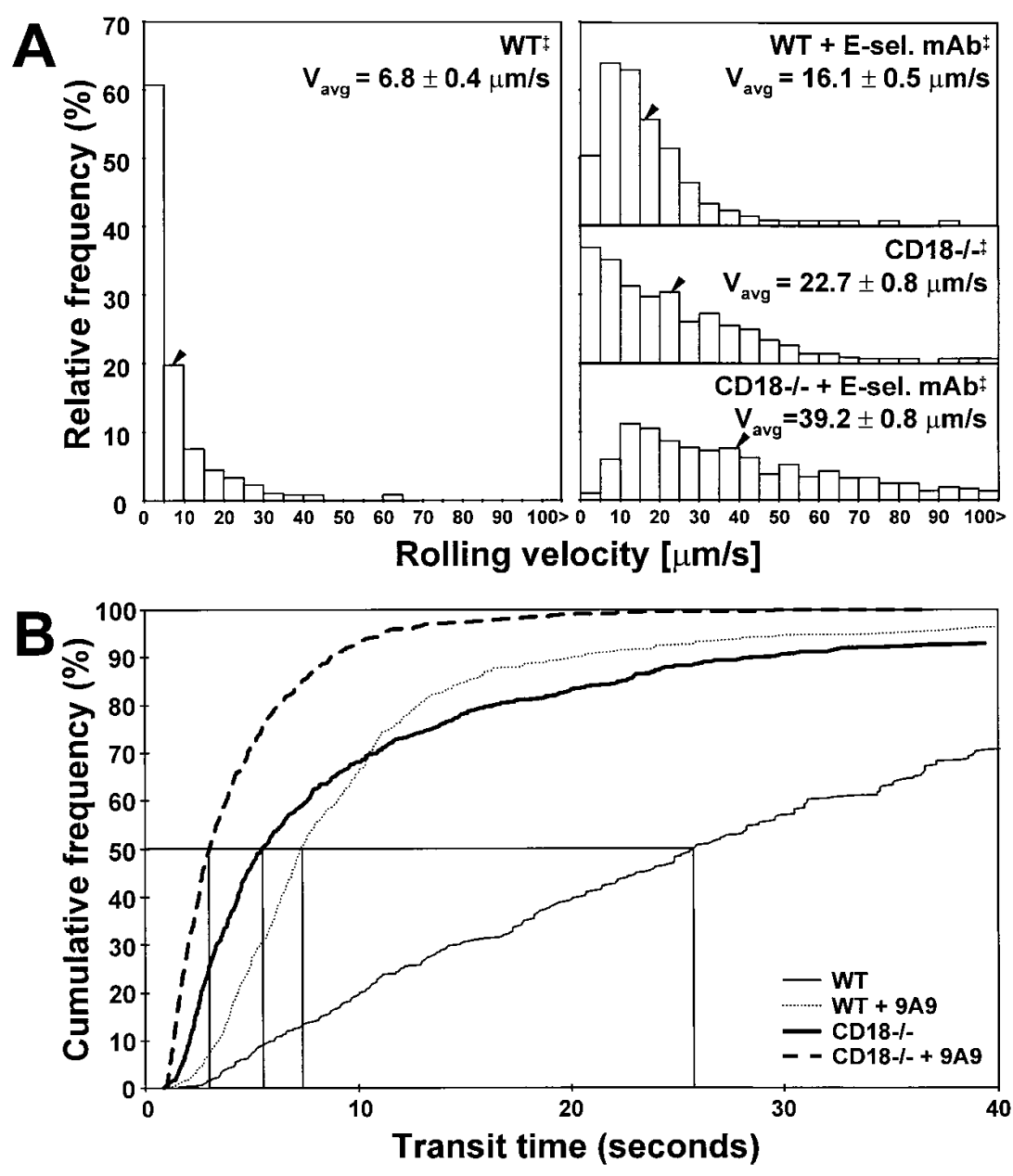

Figure 3. Leukocyte rolling velocity $(A)$ and rolling time distributions $(B)$ in TNF- $\alpha$-treated cremaster muscle venules of WT and CD18 - /mice. $(A)$ Rolling velocity distributions of WT and CD18 -/- mice with and without E-selectin $\mathrm{mAb}$ pretreatment. Arrowheads indicate mean. ${ }^{\ddagger}$, Leukocyte rolling velocities (mean \pm SEM) significantly different from all other groups $(P<0.01)$. $(B)$ Cumulative frequency curve of rolling times for WT (thin solid line), WT with E-selectin $\mathrm{mAb}$ pretreatment (thin dotted line), CD18 -/- (thick solid line), and $\mathrm{CD} 18-/$ - with E-selectin $\mathrm{mAb}$ pretreatment (thick dashed line). Median rolling time for each group indicated by vertical lines. All rolling time distributions significantly different from all other groups $(P<0.01)$. 
fect the leukocyte adhesion efficiency over the range of shear rates investigated in the present study.

Rolling velocities are inversely related to leukocyte rolling times during which the leukocytes are exposed to chemoattractants secreted by or presented on endothelial cells (28). To examine changes in leukocyte rolling time in the absence of CD18 and/or blockade of E-selectin function, we converted rolling velocities into rolling times for leukocytes rolling through a $100-\mu \mathrm{m}$ venular segment. In wild-type mice, a large fraction $(61 \%)$ of leukocytes had rolling times $>20 \mathrm{~s}$ (Fig. 3 $B)$. When E-selectin was blocked by mAb 9A9, the fraction of leukocytes with rolling times $>20 \mathrm{~s}$ decreased to $10 \%$. In CD18 null mice there was a large population of leukocytes $(47 \%)$ with short transit times $(<5 \mathrm{~s})$ (Fig. $3 \mathrm{~B})$. When E-selectin function was blocked in the absence of CD18, the fraction of leukocytes with rolling times $>20 \mathrm{~s}$ was further reduced to $1 \%$ (Fig. $3 \mathrm{~B}$ ). Furthermore, there was a complete absence of leukocytes with rolling times $>40 \mathrm{~s}$ in CD18 null mice pretreated with mAb 9A9, and the majority of leukocytes $(71 \%)$ had rolling times $<5 \mathrm{~s}$ (Fig. $3 \mathrm{~B}$ ). These findings indicate that CD18 and E-selectin cooperate to allow for longer leukocyte rolling times.

Relationship of leukocyte adhesion and rolling times. To investigate the effect of leukocyte rolling times on firm adhesion, we plotted the average rolling time through each $100-\mu \mathrm{m}$ venule against the leukocyte adhesion efficiency in the same venule. For clarity, only grouped data are shown (Fig. 4). In wild-type mice treated with TNF- $\alpha$, in which the majority of leukocytes exhibited long rolling times, the leukocyte adhesion efficiency was independent of rolling times for rolling times $>25$ s. In contrast, the adhesion efficiency became rolling time-dependent at shorter transit times in venules of these mice. Similarly, in wild-type mice pretreated with mAb 9A9 and in nontreated CD18 null mice, leukocyte adhesion efficiency was found to be strongly dependent on rolling times (Fig. 4). In CD18 null mice pretreated with mAb 9A9, no venules with average rolling times $>10 \mathrm{~s}$ were present, and adhesion efficiency was very low (Fig. 4). These data indicate that leukocyte adhesion efficiency in $\mathrm{TNF}-\alpha$-treated venules is

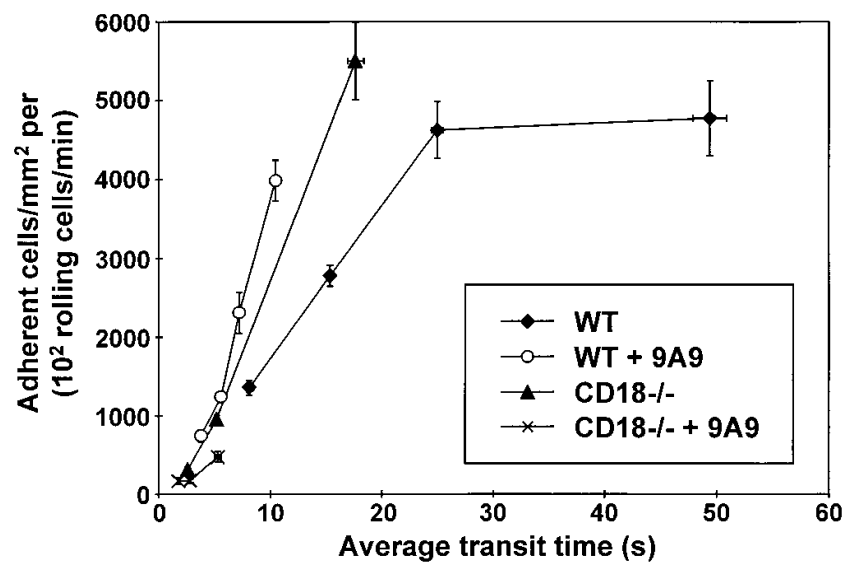

Figure 4. Adhesion efficiency (adherent cells $/ \mathrm{mm}^{2}$ per 100 rolling cells/min) as a function of average rolling time in WT mice ( $)$, WT mice with E-selectin $\mathrm{mAb}$ pretreatment $(\bigcirc), \mathrm{CD} 18-/-$ mice $(\triangle)$, and CD18 -/- mice with E-selectin mAb pretreatment $(\mathrm{x})$. Each point represents the average of between 10 and 30 venules. reduced when rolling times drop below $\sim 25 \mathrm{~s}$ for a $100-\mu \mathrm{m}$ segment.

\section{Discussion}

The present data show that CD18 and E-selectin cooperate in regulating leukocyte adhesion efficiency through their effects on leukocyte rolling times. Firm leukocyte adhesion is most efficient in the presence of both CD18 and E-selectin and is independent of rolling times at $>25 \mathrm{~s}$ for a $100-\mu \mathrm{m}$ segment of venule. In the absence of CD18 and/or E-selectin function, the adhesion efficiency is strongly dependent on rolling time. Our data show that the CD18-independent transition from leukocyte rolling to firm adhesion is possible but much less efficient than the CD18dependent adhesion pathway. The CD18-independent adhesion mechanism is able to recruit neutrophils at a level comparable with wild-type mice when sufficient numbers of rolling leukocytes are available. When both CD18 and E-selectin are absent, the leukocyte adhesion efficiency decreases dramatically, resulting in a reduction in the absolute level of leukocyte recruitment. This suggests that a threshold level of adhesion efficiency may be necessary to maintain the level of leukocyte recruitment observed in wild-type mice. When both E-selectin and CD18 are absent, rolling times become so short that leukocyte recruitment is reduced even at highly elevated levels of rolling leukocytes. However, a small population of leukocytes become firmly adherent through a CD18 and E-selectin-independent adhesion pathway. Although we did not specifically investigate this recruitment mechanism, which preferentially recruits mononuclear cells, we suspect that $\alpha_{4}$ integrin interacting with VCAM-1 may account for some of this activity $(3,29)$.

CD18 null mice have a highly elevated systemic neutrophil count that may result from impaired neutrophil emigration, cytokine release due to infections, lack of neutrophil apoptosis, or a combination of these factors (7). The number of rolling leukocytes in CD18 null mice was significantly greater than in wild-type mice, but this elevation was roughly in proportion to the increased systemic leukocyte count in CD18 null mice. We found that leukocyte firm adhesion was much less efficient in CD18 null mice than in wild-type mice in response to the inflammatory cytokine TNF- $\alpha$. Our data suggest that higher systemic leukocyte counts in CD18 null mice can be interpreted as a physiological compensatory response allowing to maintain a normal level of neutrophil recruitment despite substantial reductions in the efficiency of converting leukocyte rolling to firm adhesion.

The absence of CD18 and/or blockade of E-selectin function result in distinct changes in rolling velocity distributions. Blocking E-selectin shifts the rolling velocity distribution toward greater velocities while the variation in the distribution does not change from that observed in wild-type mice. Thus, E-selectin seems to slow down most leukocytes to velocities below $5 \mu \mathrm{m} / \mathrm{s}$, which is consistent with previous findings (10). Although it was previously appreciated that E-selectin is required for slow leukocyte rolling (10), we show here that E-selectin alone is not sufficient to mediate slow rolling. When CD18 is absent, there is both an increase in average rolling velocity as well as an increase in variance of the rolling velocity distribution. Interestingly, CD18 and E-selectin appear to serve distinct functions in mediating slow leukocyte rolling, because their absence produces an additive effect on mean leukocyte rolling velocity and variance. 
Rolling leukocytes can be activated by agonists such as PAF or IL-8 that are released from cytokine-stimulated endothelium (14, 30-32). Slower leukocyte rolling mediated by E-selectin promotes longer leukocyte rolling times, which may enhance the opportunity for interactions of leukocytes with inflammatory stimuli. This is evident in a recent study, which showed that the microapplication of chemoattractants in E-selectin-deficient mice leads to less leukocyte accumulation than in wild-type mice (33). Since CD18 integrins mediate adhesion only when conformationally activated (2), our data suggest that slowly rolling leukocytes may become partially activated by endothelial chemoattractants induced by TNF- $\alpha$. Furthermore, our results suggest that activated CD18 integrins on rolling leukocytes may bind to endothelial ligands to reduce rolling velocity. Consistent with this notion, we observed increased rolling velocities in mice lacking the IL-8 receptor (34). In these mice, the neutrophils are unable to respond to one of the major endogenous chemoattractants. The notion of CD18 participation in leukocyte rolling is also supported by increased rolling velocities after CD18 blockade in an isolatedperfused cat mesentery preparation (24), and by a partial effect of CD18 antibodies on leukocyte rolling in rat mesenteric venules at reduced shear rate (35).

While L-selectin predominantly mediates capture and leukocyte rolling at fast velocities $(>100 \mu \mathrm{m} / \mathrm{s})$, P-selectin promotes leukocyte rolling at slower velocities $(20-50 \mu \mathrm{m} / \mathrm{s})$, and E-selectin supports leukocyte rolling at $<5 \mu \mathrm{m} / \mathrm{s}$. The importance of slow rolling bridging the gap between L-selectin-mediated capture and CD18-mediated firm adhesion and arrest is evident in E- and P-selectin double mutant mice, where neutrophil rolling and recruitment are dramatically compromised (4). The necessity for a velocity gradient, from L-selectin through $\mathrm{P}$ - and E-selectin to CD18 integrins promoting leukocyte arrest, has been suggested in a recent review article (36). Here, we show that slow rolling mediated by E-selectin and CD18 integrins is a required step in this velocity gradient sequence.

Rolling neutrophils may integrate multiple signals received at slightly different times that eventually cross a threshold that triggers the mostly integrin-mediated arrest of the rolling neutrophils. This concept suggests that slow rolling is necessary to provide opportunities for rolling neutrophils to interact with chemoattractants during their transit through an inflamed area. Consistent with this concept, our data show that CD18 and E-selectin appear to exert their effect on the regulation of leukocyte adhesion efficiency through their effects on leukocyte rolling times. Firm leukocyte adhesion is most efficient in the presence of both CD18 and E-selectin. In the absence of CD18 and/or E-selectin function, the adhesion efficiency is strongly dependent on rolling time. The sharp decrease in leukocyte rolling times observed in the absence of both CD18 and E-selectin results in a corresponding reduction in the efficiency of leukocyte recruitment. When both E-selectin and CD18 are absent, rolling times become so short that leukocyte recruitment is reduced even at highly elevated levels of rolling leukocytes. Taken together, our data indicate that longer rolling times mediated by both CD18- and E-selectin-dependent adhesion are necessary for the efficient transition from rolling to firm adhesion. These findings are consistent with rolling leukocytes integrating the chemoattractant stimuli presented on the endothelial surface, i.e., PAF and IL-8. We propose a modified leukocyte adhesion cascade model (Fig. 5) to account for these findings.
A

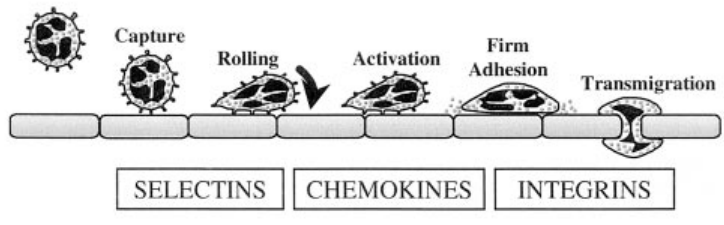

B

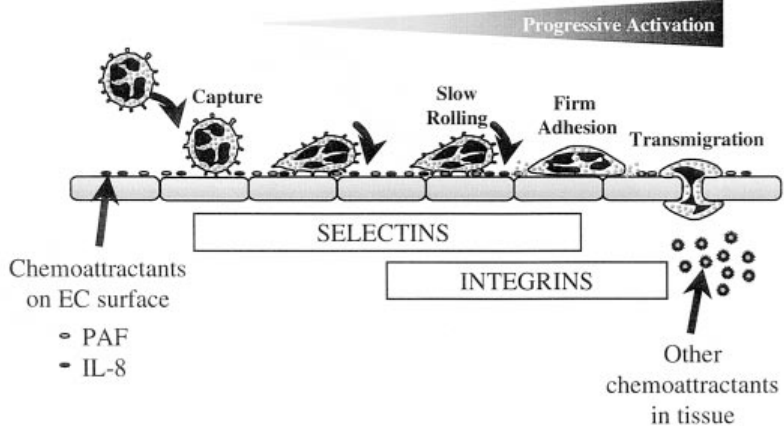

Figure 5. Previous $(A)$ and modified $(B)$ leukocyte adhesion cascade, based on the current findings.

In TNF- $\alpha$-induced inflammation, the rate-limiting step in the leukocyte adhesion cascade is the transition from rolling to firm adhesion, because leukocyte recruitment into the interstitial tissue roughly follows the pattern observed for accumulation of intravascular leukocytes. Contrary to the currently held paradigm, we show that both CD18 and E-selectin are involved in converting rolling to firm adhesion. Slow leukocyte rolling causes long leukocyte rolling times, which appear to be necessary for efficient leukocyte recruitment in response to a physiological inflammatory stimulus. In the absence of CD18, the contribution of E-selectin in the transition from leukocyte rolling to firm adhesion becomes critical. Our study establishes leukocyte rolling time as the unifying parameter determining leukocyte adhesion in TNF- $\alpha$-induced inflammation and provides a theoretical foundation suitable for future development of a quantitative mathematical model of inflammation.

\section{Acknowledgments}

We thank Dr. Barry Wolitzky, Hoffmann-LaRoche, Inc., Nutley, NJ, for providing $\mathrm{mAb} 9 \mathrm{~A} 9$ for this study and Dr. C.L. Ramos for valuable discussion.

Funding for this study was provided by National Institutes of Health grants HL 54136 to K. Ley and AI-32177 to A.L. Beaudet. U. Jung is supported by a predoctoral fellowship, USPHS Training Grant T-32 HL07284 to B.R. Duling.

\section{References}

1. Butcher, E.C. 1991. Leukocyte-endothelial cell recognition-three (or more) steps to specificity and diversity. Cell. 67:1033-1036.

2. Springer, T.A. 1995. Traffic signals on endothelium for lymphocyte recirculation and leukocyte emigration. Annu. Rev. Physiol. 57:827-872. 
3. Kanwar, S., D.C. Bullard, M.J. Hickey, C.W. Smith, A.L. Beaudet, B.A. Wolitzky, and P. Kubes. 1997. The association between $\alpha_{4}$-integrin, P-selectin, and E-selectin in an allergic model of inflammation. J. Exp. Med. 185:10771087.

4. Bullard, D.C., E.J. Kunkel, H. Kubo, M.J. Hicks, I. Lorenzo, N.A. Doyle, C.M. Doerschuk, K. Ley, and A.L. Beaudet. 1996. Infectious susceptibility and severe deficiency of leukocyte rolling and recruitment in E-selectin and P-selectin double mutant mice. J. Exp. Med. 183:1-8.

5. Frenette, P.S., T.N. Mayadas, H. Rayburn, R.O. Hynes, and D.D. Wagner. 1996. Susceptibility to infection and altered hematopoiesis in mice deficient in both P- and E-selectins. Cell. 84:563-574.

6. Arfors, K.-E., C. Lundberg, L. Lindbom, K. Lundberg, P.G. Beatty, and J.M. Harlan. 1987. A monoclonal antibody to the membrane glycoprotein complex CD18 inhibits polymorphonuclear leukocyte accumulation and plasma leakage in vivo. Blood. 69:338-340.

7. Scharffetter-Kochanek, K., H. Lu, D.C. Bullard, K.E. Norman, N. van Nood, S. Grabbe, M. McArthur, I. Lorenzo, K. Mahnke, K. Ley, et al. 1998. Spontaneous skin ulceration and defective T cell function in CD18 null mice. $J$. Exp. Med. 188:119-131.

8. Jung, U., and K. Ley. 1997. Regulation of E-selectin, P-selectin, and intercellular adhesion molecule 1 expression in mouse cremaster muscle vasculature. Microcirculation. 4:311-319.

9. Ley, K., D.C. Bullard, M.L. Arbonés, R. Bosse, D. Vestweber, T.F. Tedder, and A.L. Beaudet. 1995. Sequential contribution of L- and P-selectin to leukocyte rolling in vivo. J. Exp. Med. 181:669-675.

10. Kunkel, E.J., and K. Ley. 1996. Distinct phenotype of E-selectin-deficient mice. E-selectin is required for slow leukocyte rolling in vivo. Circ. Res. 79:1196-1204

11. Jung, U., D.C. Bullard, T.F. Tedder, and K. Ley. 1996. Velocity differences between L- and P-selectin-dependent neutrophil rolling in venules of mouse cremaster muscle in vivo. Am. J. Physiol. 271:H2740-2747.

12. Mayadas, T.N., R.C. Johnson, H. Rayburn, R.O. Hynes, and D.D. Wagner. 1993. Leukocyte rolling and extravasation are severly compromised in P-selectin deficient mice. Cell. 74:541-554.

13. Alon, R., D.A. Hammer, and T.A. Springer. 1995. Lifetime of the P-selectin carbohydrate bond and its response to tensile force in hydrodynamic flow. Nature. 374:539-542.

14. Zimmerman, G.A., S.M. Prescott, and T.M. McIntyre. 1992. Endothelial cell interactions with granulocytes: tethering and signaling molecules. Immunol. Today. 13:93-100.

15. Norton, C.R., J.M. Rumberger, D.K. Burns, and B.A. Wolitzky. 1993. Characterization of murine E-selectin expression in vitro using novel antimouse E-selectin monoclonal antibodies. Biochem. Biophys. Res. Commun. 195:250-258.

16. Pries, A.R. 1988. A versatile video image analysis system for microcirculatory research. Int. J. Microcirc. Clin. Exp. 7:327-345.

17. Lipowsky, H.H., and B.W. Zweifach. 1978. Application of the "two-slit" photometric technique to the measurement of microvascular volumetric flow rates. Microvasc. Res. 15:93-101.

18. Reneman, R.S., B. Woldhuis, M.G.A. oude Egbrink, D.W. Slaaf, and G.J. Tangelder. 1992. Concentration and velocity profiles of blood cells in the microcirculation. In Advances in Cardiovascular Engineering. N.H.C. Hwang, editor. 25-40.

19. Zhao, Y.H., S. Chien, and R. Skalak. 1995. A stochastic model of leuko- cyte rolling. Biophys. J. 69:1309-1320.

20. Kunkel, E.J., U. Jung, D.C. Bullard, K.E. Norman, B.A. Wolitzky, D. Vestweber, A.L. Beaudet, and K. Ley. 1996. Absence of trauma-induced leukocyte rolling in mice deficient in both P-selectin and intercellular adhesion molecule-1 (ICAM-1). J. Exp. Med. 183:57-65.

21. Weber, C., C.F. Lu, J.M. Casasnovas, and T.A. Springer. 1997. Role of $\alpha_{\mathrm{L}} \beta_{2}$ integrin avidity in transendothelial chemotaxis of mononuclear cells. $J$. Immunol. 159:3968-3975.

22. Burns, A.R., D.C. Walker, E.S. Brown, L.T. Thurmon, R.A. Bowden, C.R. Keese, S.I. Simon, M.L. Entman, and C.W. Smith. 1997. Neutrophil transendothelial migration is independent of tight junctions and occurs preferentially at tricellular corners. J. Immunol. 159:2893-2903.

23. Lu, H., C.W. Smith, J. Perrard, D.C. Bullard, L. Tang, S.B. Shappell, M.L. Entman, A.L. Beaudet, and C.M. Ballantyne. 1997. LFA-1 is sufficient in mediating neutrophil emigration in Mac-1-deficient mice. J. Clin. Invest. 99: 1340-1350.

24. Perry, M.A., and D.N. Granger. 1991. Role of CD11/CD18 in shear rate-dependent leukocyte-endothelial cell interactions in cat mesenteric venules. J. Clin. Invest. 87:1798-1804.

25. Lawrence, M.B., C.W. Smith, S.G. Eskin, and L.V. McIntire. 1990. Effect of venous shear stress on CD18-mediated neutrophil adhesion to cultured endothelium. Blood. 75:227-237.

26. Lawrence, M.B., and T.A. Springer. 1991. Leukocytes roll on a selectin at physiologic flow rates: distinction from and prerequisite for adhesion through integrins. Cell. 65:859-873.

27. Damiano, E.R., J. Westheider, A. Tözeren, and K. Ley. 1996. Variation in the velocity, deformation, and adhesion energy density of leukocytes rolling within venules. Circ. Res. 79:1122-1130.

28. Middleton, J., S. Neil, J. Wintle, I. Clark-Lewis, H. Moore, C. Lam, M. Auer, E. Hub, and A. Rot. 1997. Transcytosis and surface presentation of IL-8 by venular endothelial cells. Cell. 91:385-395.

29. Sriramarao, P., U.H. von Andrian, E.C. Butcher, M.A. Bourdon, and D.H. Broide. 1994. L-selectin and very late antigen-4 integrin promote eosinophil rolling at physiological shear rates in vivo. J. Immunol. 153:4238-4246.

30. Huber, A.R., S.L. Kunkel, R.F. Todd III, and S.J. Weiss. 1991. Regulation of transendothelial neutrophil migration by endogenous interleukin-8. Science. 254:99-102.

31. Bussolino, F., G. Camussi, and C. Baglioni. 1988. Synthesis and release of platelet-activating factor by human vascular endothelial cells treated with tumor necrosis factor or interleukin 1 alpha. J. Biol. Chem. 263:11856-11861.

32. Nourshargh, S., S.W. Larkin, A. Das, and T.J. Williams. 1995. Interleukin-1-induced leukocyte extravasation across rat mesenteric microvessels is mediated by platelet-activating factor. Blood. 85:2553-2558.

33. Ley, K., M. Allietta, D.C. Bullard, and S. Morgan. 1998. The importance of E-selectin for firm leukocyte adhesion in vivo. Circ. Res. 83:287-294.

34. Morgan, S.J., M.W. Moore, G. Cacalano, and K. Ley. 1997. Reduced leukocyte adhesion response and absence of slow leukocyte rolling in interleukin-8 receptor-deficient mice. Microvasc. Res. 54:188-191.

35. Gaboury, J.P., and P. Kubes. 1994. Reductions in physiologic shear rates lead to CD11/CD18-dependent, selectin-independent leukocyte rolling in vivo. Blood. 83:345-350.

36. Kansas, G.S. 1996. Selectins and their ligands: current concepts and controversies. Blood. 88:3259-3287. 